\section{Adding to the cannabis debate: Comment on various Centrall Drug Authority papers}

This contribution addresses the following documents published in this and a previous edition of the SAMJ:

- The Central Drug Authority (CDA)'s position paper on cannabis ${ }^{[1]}$

- The CDA's position paper on harm reduction ${ }^{[2]}$

- The CDA's response ${ }^{[3]}$ to the editorial ${ }^{[4]}$ commenting on the CDA's position statement on cannabis.

As there is considerable overlap between the contents of the above documents, this article tries to avoid covering all the arguments put forward both in these documents and in the author's comment ${ }^{[4]}$ on the CDA's position statement on cannabis. Instead, it sets out to inform medical professionals and civil society why the incorporation of illicit drugs into the existing regulatory framework of drug control is the only holistic way to implement comprehensive harm reduction measures and bring an end to the 'war on drugs'.

\section{Harm reduction}

Most of the CDA's recommendations in respect of a more humanistic approach to harm reduction should be supported. It is to be hoped that its increasingly progressive attitude to drug issues will give the medical profession a dominant role in policy-making within the structures of the CDA, in parliament and in other decision-making forums.

For too long the criminal justice system has had an overriding influence on the way governments have created harmful drug laws and the manner in which these laws have been implemented. Drug use should be primarily a public health issue, not a criminal one. Illicit drug use is classified as a crime, but since it is victimless, it should not be a crime at all. The consumption of illicit psychoactive drugs should be no more a crime than the use of tobacco or alcohol.

\section{The United Nations Conventions on drugs}

The CDA's call for more evidence before it will back the implementation of legal regulation, as well as its advocacy for the continued adherence to the harmful, irrational and outdated United Nations (UN) Single Convention on Drugs of $1961^{[5]}$ (and related conventions), needs to be addressed.

The UN Convention on Psychotropic Substances, $1971^{[6]}$ classifies a range of psychotropic drugs into four main schedules depending on their perceived harmfulness - the scheduling of a psychotropic drug determines the degree to which it is controlled. Those drugs considered to have medicinal value are allocated different schedules to those that are deemed to have none. Examples of the drugs that occupy the latter schedules are cannabis, methamphetamine and LSD. The glaring omission from these comprehensive lists is the most harmful drug of all, alcohol. Excluding alcohol from the UN schedules has more to do with political expediency and alcohol's culturally sanctioned status than concern for its addiction potential or harmfulness.

\section{Legal regulation is a rational, humanistic alternative to the war on drugs}

The only holistic, proven and rational way to deal with the undesirable consequences of the human penchant to use psychoactive substances ${ }^{[7]}$ is to legalise these drugs and include them in the flexible framework known as 'legal regulation'. Legal regulation is a wellknown and widely applied legal and administrative process that most countries use to tax and control the production, distribution and sale of prescription drugs, alcohol, tobacco and other drugs.

\section{Definition of legal regulation}

'Legalisation' and 'legal regulation' differ. While legalisation is merely a process that makes something that is illegal legal, legal regulation provides a regulatory framework that governs the production, supply and use of drugs - any activity outside this framework remains prohibited.

A widely held misconception is that legal regulation is a radical idea; it is therefore sometimes characterised as a 'liberalisation' or 'relaxation' of the law. However, it is in fact the opposite; it is about bringing the drug trade within the law - with strict controls that are impossible to impose when prohibition prevails.

Legal regulation certainly does not imply a free-for-all that makes drugs available to anyone, anywhere and at any time. Instead, legal regulation enables governments to control where drugs are grown, manufactured and sold, and who can access them. It also allows the authorities to monitor and specify the quality, strength and composition of the products in the marketplace, something that is impossible to do under the laws of prohibition.

Although legal regulation is an imperfect system of drug control, it is far preferable to the total prohibition of any drug, and preferable to its milder version, decriminalisation. This was clearly demonstrated by the fiasco of the 1920s/1930s alcohol prohibition laws in the USA and their subsequent repeal. At present, almost every country (apart from a few where the prohibition of alcohol still exists) uses a variation of legal regulation to control the trade and use of alcohol products. Prior to their signing of the UN's Single Convention on Drugs in 1961, most countries included cannabis, opium and other drugs in this effective, adaptable framework. Since 1961, the 185 countries that signed the Convention have been expected to implement its irrational and harmful rules, which exclude two of the most harmful psychoactive drugs, alcohol and tobacco. ${ }^{[8,9]}$

That an extremely harmful drug such as alcohol can be regulated, controlled and taxed, with a relatively low background level of crime associated with its production and trade, stands in stark contrast to the trillion-dollar international illicit drug industry that is dominated by organised crime syndicates, contributes nothing to a state's fiscus and costs the global community billions of dollars annually.

Anyone who takes a dispassionate view of this obvious state of affairs cannot but agree that legal regulation is far preferable to prohibition.

\section{Aims of legal regulation}

The legal regulation of 'recreational' psychoactive drugs strives to protect the young and vulnerable by controlling their availability, and to educate the public about their potential harms. It aims to reduce crime by diverting the profits currently generated and retained by the illicit drug trade to the state fiscus. This tax revenue could finance education, rehabilitation, medical services and support effective, humanistic crime-fighting initiatives, and provide for other expenses associated with the regulation of recreational drugs.

Public health relating to these products would be improved by ensuring that products are pure and standardised, and through the provision of health education and other pertinent information.

Legal regulation provides a way to protect human rights by abolishing unjust laws that discriminate against those who use psychoactive substances for recreational and medicinal purposes, removing the fear of prosecution.

Existing laws make it virtually impossible to control any of the links in the illicit drug supply chain. At present, anyone of any age can buy drugs - drug dealers don't ask for ID! Under a system of legal regulation, many activities, such as sales to minors, would remain illegal and subject to sanctions. Proponents of legal regulation generally support the implementation of improved, stricter controls over legal drugs such as alcohol, tobacco and other recreational drugs. 
However, for legal regulation to be optimally effective it needs to be complemented by improvements in public health, drug use education, and addiction prevention and treatment. Society also needs to focus attention on the underlying psychosocial causes of addiction such as mental illness, adverse childhood experiences, poverty, inequality and social exclusion.

The change to legal regulation from the current status need not happen overnight. It may be cautious, phased in and adapted according to the results. If policies do not work, they may be revisited and, where necessary, changed.

Although legal regulation alone will not solve the many problems related to either currently legal or illicit drugs, it provides a far better alternative to the existing crime and social problems caused by drug prohibition. Local and global experience over the past 100 years demonstrates that prohibition cannot achieve these aims, and in fact actively undermines them.

Legal regulation does what the war on drugs has failed to do. If properly implemented, it could decrease drug use among children, foster harm reduction measures in drug users, reduce the stigmatisation of addicts, curtail infectious disease transmission, dramatically reduce drug-related deaths, control the quality, sale and availability of drugs, substantially decrease drug-related criminal activity, reduce the profits of organised crime, lessen the opportunity for corruption among law enforcement officials, lower the cost of law enforcement and reduce prison populations. ${ }^{[10]}$ It also allows for the more effective implementation of drug education programmes and drug-related health services.

\section{Examples of effective legal regulation \\ Alcohol}

Sweden's alcohol laws provide an example of the ways in which a specific country can adapt legal regulation to its own requirements. Its laws allow the private sector to produce and sell products with an alcohol concentration of less than 3.5\%. Products with an alcohol concentration above that level can be purchased only from a limited number of state-owned liquor stores.

That South Africa (SA) and other countries regulate the use, production, sale and advertising of alcohol and tobacco in different ways demonstrates the flexibility conferred by legal regulation.

\section{Tobacco}

In contrast to the rise in the consumption of illicit drugs, the global use of tobacco has been declining steadily. ${ }^{[11]}$ This reduction is being achieved without blanket bans or criminalising smokers. Rather, it is the result of programmes that include appropriate education, advertising constraints and stricter market regulation, only possible because tobacco is a legal product.

\section{Cannabis}

The legalisation of cannabis in US states such as Colorado demonstrates how easy it is to incorporate a previously illicit substance into the framework of legal regulation. In Spain, cannabis social clubs ${ }^{[12]}$ have been in existence for over a decade. These clubs are noncommercial organisations of cannabis users who grow, cultivate and share enough cannabis of good quality to meet their personal needs. This type of consumer-focused, non-profit model could easily be incorporated into legal regulation structures. It would also allay the fears of the CDA and others that legalising cannabis would open the doors for imagined commercial entities such as 'Big Cannabis' (cf. 'Big Tobacco') to arise and dominate the market.

Levels of drug use are often equated with levels of drug harm, but the vast majority of drug use is non-problematic. ${ }^{[13-15]}$ Rather than narrowly focusing on reducing use, policy should seek to reduce overall harm. Although decriminalisation mitigates the harms experienced by drug users, unlike legal regulation, it does not address the extensive damage and suffering caused by the massive criminal structures that dominate the drug trade.

We have a choice: the drug trade can be controlled either by criminals or governments. Legal regulation is the only substantiated, holistic and humanistic way to deal with the issues relating to the health benefits and harms of recreational and other drugs, their social impact and the vast crime networks that the current laws help to sustain.

With its seemingly endless search for more and more evidence and its call for an end to the war on drugs, it is hoped that the CDA will move away from confirmation bias that emphasises the pharmacological harms of illicit drugs over the widespread damage caused by the current drug laws themselves. Instead, it should acknowledge that the evidence it claims to be looking for is to be found in the laws and extensive experience of most countries' efforts to manage currently licit psychoactive drugs such as alcohol, tobacco and prescription drugs.

Continuing to prevaricate by emphasising the dangers of drugs (over and above the best solutions for dealing with the wider drug issues) gives the CDA's political masters the opportunity to use that unbalanced 'evidence' to promote an agenda that runs counter to the CDA's new progressive approach to drug law reform.

Let us not forget that it was less than a decade ago that the SA government tried to further its own perverse agenda by prejudicially emphasising and exaggerating the adverse effects of the antiretroviral drug nevirapine to severely restrict its use in the fight against HIV/ AIDS. It took a non-medical non-governmental organisation, the Treatment Action Campaign, to force the government to provide this effective drug. ${ }^{[16]}$

Those of us in the medical profession, especially those working in academic and government structures, need to avail ourselves of all the evidence pertaining to the public health, criminal and social effects of the current drug laws and ensure that this time we are the ones who speak the full truth to power.

\section{Keith Scott}

Simon's Town, Cape Town, South Africa zscottz@gmail.com

1. Stein D, for the Executive Committee of the Central Drug Authority Position statement on cannabis. Afr Med J 2016:106(6):569-570. DOI:10.7196/SAMJ.2016.v106i6.10863

2. Stein D, Manyedi E, for the Executive Committee of the Central Drug Authority. Psychoactive substances: Position statement on harm reduction. S Afr Med J 2016;106(9):836. DOI:10.7196/ SAMI.2016.v106i9.11223

3. Stein D, Manyedi E, for the Executive Committee of the Central Drug Authority. Position statement on cannabis: A step forwards. S Afr Med J 2016;106(9):837. DOI:10.7196/SAMJ.2016.v106i9.11222

4. Scott K. Comment on the Central Drug Authority's position statement on cannabis. S Afr Med J 2016;106(6):545-546. DOI:10.7196/SAMJ.2016.v106i6.11036

5. United Nations. Single Convention on Narcotic Drugs, 1961. New York: UN, 1961

6. United Nations. Convention on Psychotropic Substances, 1971. New York: UN, 1971.

7. Crocq M. Historical and cultural aspects of man's relationship with addictive drugs. Dialogues Clin Neurosci 2007;9(4):355-361.

Nutt DJ, King LA, Phillips LD, Independent Scientific Committee on Drugs. Drug harms in the UK: A multicriteria decision analysis. Lancet 2010;376(9752):1558-1565. DOI:10.1016/s0140-6736(10)61462-6 Lachenmeiera D, Rehm J. Comparative risk assessment of alcohol, tobacco, cannabis and other illicit drugs using the margin of exposure approach. Sci Rep 2015;5:8126. DOI:10.1038/srep08126

10. Goga K. The drug trade and governance in Cape Town. Pretoria: Institute for Security Studies, 2014:263.

11. World Health Organization. Global Report on Trends in Tobacco Smoking 2000 - 2025. Geneva: WHO, 2015.

Alonso M. Cannabis Social Clubs in Spain. Amsterdam: Transnational Institute, 2011

13. Robins L, Helzer J, Davis D. Narcotic use in Southeast Asia and afterward. An interview study of 898 Vietnam returnees. Arch Gen Psychiatry 1975;32(8):955-96

14. Clarke H, Soneji N, Ko D, Yun L, Wijeysundera D. Rates and risk factors for prolonged opioid use after major surgery: Population based cohort study. BMJ 2014;348:g1251. DOI:10.1136/ bmj.g1251

15. Mann J. British drugs survey 2014: Drug use is rising in the UK - but were not addicted. The Guardian Newspaper, 5 October 2014

16. Constitutional Court of South Africa. Case CCT 8/02. Johannesburg: Constitutional Court of SA, 2002. 